\title{
Bohemian Cultural Scenes and Creative Development of Chinese Cities: An Analysis of 65 Cities Using Cultural Amenity Data
}

\author{
Jun Wu ${ }^{1, * \mathbb{C}}$, Hao Zheng ${ }^{2}$, , Tong Wang ${ }^{3 \oplus \mathbb{D}}$ and Terry Nichols Clark ${ }^{3}$ \\ 1 Department of Sociology, Beijing Population Institute, Beijing Administration Institute, Beijing 100044, China \\ 2 Department of Sociology, Beijing Administration Institute, Beijing 100044, China; beiwenshu@126.com \\ 3 Department of Sociology, University of Chicago, Chicago, IL 60637, USA; wangt18@uchicago.edu (T.W.); \\ tnclark@uchicago.edu (T.N.C.) \\ * Correspondence: 18600102719@163.com; Tel.: +86-186-0010-2719
}

\section{check for} updates

Citation: Wu, J.; Zheng, H.; Wang, T.; Clark, T.N. Bohemian Cultural Scenes and Creative Development of Chinese Cities: An Analysis of 65 Cities Using Cultural Amenity Data. Sustainability 2021, 13, 5260. https:// doi.org/10.3390/su13095260

Academic Editors: Clemente J.

Navarro Yáñez, María

Jesús Rodríguez-García and

Miguel Amado

Received: 24 March 2021

Accepted: 29 April 2021

Published: 8 May 2021

Publisher's Note: MDPI stays neutral with regard to jurisdictional claims in published maps and institutional affiliations.

Copyright: (c) 2021 by the authors. Licensee MDPI, Basel, Switzerland. This article is an open access article distributed under the terms and conditions of the Creative Commons Attribution (CC BY) license (https:// creativecommons.org/licenses/by/ $4.0 /)$.

\begin{abstract}
There has been a cultural turn in urban development, as an increasing number of scholars are stressing the importance of culture in urban research and policy agendas. Specifically, the bohemian cultural scene could drive an integral cultural policy approach between the cultural scenes city and the creative city approach. Based on amenities data from 65 major Chinese cities, this paper investigates the relationship between bohemian cultural scenes and creative development of Chinese cities as well as regional differences using tree-based model, ordinary least squares (OLS) and truncated regression, and provides conceptual and quantitative support for a bohemian cultural scenes policy. Factor analysis suggests the bohemian cultural scene in Chinese cities consists of two dimensions: self-expression and charisma. According to regression results, bohemian scenes significantly promote urban creative development; specifically, charisma has a stronger impact on urban creativity than self-expression. There are also significant regional differences: northern and eastern cities should focus on the development of the charismatic dimension, creative subjects should adjust away from prudent industriousness and practice dynamic experimentalism; whereas southern cities should focus on the self-expressive dimension, and continue to promote tolerance, inclusivity and expressive practice. Finally, the bohemian scenes policy demands an integral policy approach sensitive to the existing socioeconomic context: policymakers should incorporate specific amenities into existing qualities of local spaces and cultural consumption to stimulate creative development.
\end{abstract}

Keywords: bohemian; creative city; cultural scenes; integral urban policies; urban cultural policies

\section{Introduction}

China experienced exponential growth in urban development in the past few decades, as its urbanization rate increased from $17.9 \%$ in 1978 to $60.6 \%$ in 2019 . As the key driver of urban development gradually shifts from industrial production to creativity and innovation [1-4], China's urban policy is facing new challenges. In China and more generally in East Asia, urban innovation is based on local competition led by the government [5], which is not only related to the creativity of local industries and talents, but is also closely related to the government's development strategy and cultural planning [6]. Household registration policies have played a key role in attracting creative talents in Chinese cities. Specifically, the household registration policies of Shanghai, Shenzhen and Xi'an are relatively loose compared with cities of the same level, effectively attracting creative talents, whereas Beijing's relatively conservative policies have curbed the influx of creative talents to a certain extent $[7,8]$. On the other hand, the government has employed policies to support small businesses through public services and credit guarantees, which enhances local creative development. However, in the new era of global urban development, could traditional developmental and redistribution policies that rely largely on the allocation 
of production factors support the next phase of urban creative development? There has been a cultural turn in urban development. As cities transition from the industrial to the post-industrial stage, traditional urban policies are increasingly limited in stimulating urban creative development, whereas cultural and consumption practices, once peripheral to urban growth, are brought to the center of urban research and policy agendas $[1,9,10]$. The economic growth policy paradigm lacking "quality of life" perspectives, such as cultural creativity and consumption, is no longer sufficient to fully support the transformation and development of China's metropolises. Edward Gleaser, Jianing Zhang and Lixun Li, and Qun Wang and Yelan Dong and others have emphasized a policy approach centered on social tolerance [10-12]. According to Gleaser, creative talents are more likely to be concentrated in cities with a greater level of tolerance. In high-density cities, face-to-face interpersonal communication and multicultural exchange tend to generate creative processes and human progress [10]. Similarly in China, Zhang and Li find that tolerance and inclusiveness in the Pearl River Delta region have a positive impact on the spatial distribution of the highly educated [11]; Wang and Dong find that with the gradual increase in local consumption capacity, a flexible and tolerant living environment plays a significant role in promoting the agglomeration of the creative class in Anhui Province [12]. In addition to urban infrastructures, such as high-quality universities and research and development institutions, a tolerant social atmosphere has been proven to promote urban creative development [13-16]. However, a policy perspective centered around promoting tolerance also has certain limitations, since it is not a systematic and explicitly oriented integral policy agenda that incorporates urban spaces, as well as residents and production and consumption activities therein.

Some scholars have put forth a more systematic urban policy approach. Silver and Clark argue that in the context of globalization, individualization, the rise of the middle class and post-industrialization, the cultural scene has become a crucial factor in urban policymaking [17]. Navarro and Clark argue that "cultural policy" is transversal, in that it is amenable to finding coalition from both sides of the classical "pro-growth"-"social redistribution" divide in urban policy [18]. More specifically, three paradigms of local cultural policy are introduced: the creative city, the city as a cultural scene and educational city. In particular, the bohemian scene is a multi-dimensional cultural scene, driving a cultural policy approach between the creative city and cultural scene city. In a bohemian scene, people are more likely to challenge conventions and express themselves equally. With the development of the new economy, the bohemian scene has become a laboratory for creative styles and a magnet for creative workers [17]. People can easily form social networks, generate unconventional ideas and foster new projects and new companies, along with other drivers of economic growth. The agglomeration of creative talents will, in turn, increase cultural consumption and bohemian lifestyles and ideas, which further promotes economic growth, and establishes a virtuous cycle between creativity and economic growth. For instance, the successes of creative development in Chicago's Wicker Park or Toronto's Queen Street West both benefited from an integral policy perspective around the bohemian scene [17]. Do bohemian scenes similarly promote creative development of metropolises in China?

Although Jun Wu, Ning Wang, Bo Chen, Ji Qi and others [18-22] have introduced scenes theory and the bohemian scene as a research framework into China, there has been little to no empirical research to verify the relationship between bohemianism and urban creativity. The purpose of this paper is to verify the driving effect of bohemian scenes on the creative development of cities in different regions of China, and to provide conceptual and quantitative support for the formulation of a bohemian cultural scene policy approach. The main focus of this paper is not to give specific policy recommendations, but to summarize how to incorporate the concept and data of bohemian scene into policymaking, so that policymakers could adjust measures according to varying local contexts; and, moreover, to encourage more mayors and administrators to consider the importance of scenes and cultural policy [17]. This paper is organized in the following manner: Section 2 examines 
the state of the field pertinent to the current study, specifically literature on urban policy, urban creativity, cultural scenes and bohemianism. Section 3 explains the research design of this study, including key variables, sample selection as well as methodology. Section 4 presents main research results from tree-based method and regression models. Section 5 presents policy implications of research results and perspectives for future research.

\section{Review of Literature}

The cultural scenes policy approach drives urban creative development by fostering a cultural context attractive to creative talents and enterprises. Traditional economic development and educational policies are both limited in promoting urban creative development and innovation. Thus, an integral culture-oriented urban policy approach is required. The aggregation of urban creative projects not only depends on granting preferential subsidies, but also hinges on the particular cultural context of the city $[23,24]$, which is mainly determined by "soft" urban cultural facilities, such as "city buzz", cultural amenities and social tolerance and diversity [25-27]. These components of urban cultural context are shown to play a decisive role in attracting creative talents and promoting innovation $[28,29]$.

Here, urban context is closely related to the concept of urban "cultural scene", which captures distinct lifestyles and cultures in urban spaces. It is an integral concept that combines culture, technology, talented individuals, consumption and so on, endowing esthetic significance to a place. A scene consists of a diverse combination of amenities and activities [17]. Through cultural and artistic consumption, cultural scenes turn cities into creative highlands, and, in turn, hatch creative products, consumption activities and creative ideas [30]. Specifically, the "city as a cultural scene" is considered one of the three main approaches of local cultural policy by Navarro and Clark [18]. The cultural scenes policy approach centers on cultural consumption: it focuses on consumers and formulates policies by responding to the demands of cultural lifestyle and consumption of distinct social groups. It is important to note that the cultural scenes approach as a "transversal policy" effectively bridges the classical divide between "pro-growth" and "social redistribution" in local urban policies, breaking the competitive relationship between the two policy advocates and forming an integral policy agenda. Specifically, on the one hand, a scene composed of cultural amenities and activities induces regional economic growth by increasing consumption and employment, which meets the purpose of the "economic growth" approach; on the other hand, diversified cultural consumption opportunities promote social integration of various groups of people by encouraging cultural participation of the public, which meets the goal of the "social redistribution" and social welfare approach [18]. Thus, cultural scenes can be used to guide an integral policy approach that centers on the cultural participation of congregations of creative individuals and the impact of cultural consumption and leisure on urban creativity and innovation [31].

The bohemian scene is a new driving force of urban creative development. "Bohemian culture" originated in 19th century Paris and refers to "an artistic, unconventional, frugal, nomadic, and anti-establishment lifestyle" [32]. When cities enter the post-industrial stage, there is an expansion of new industries oriented toward creativity, service and consumption. Different from production and manufacturing workers of the industrial age, the practitioners of these new industries tend to embrace bohemianism, due to its emphasis on individuality, freedom, tolerance and diversity. Thus, bohemian culture has been associated with urban creative development. In addition, bohemian culture requires timely response to various new situations, and encourages people to make the best use of their talents and succeed through individuality [17]. However, bohemian culture does not unilaterally imply pursuing transgression or idiosyncrasy, for example, in Toronto, the scenes with the strongest bohemian characteristics are often directly related to values of rationalism and pragmatism [17]. Therefore, bohemianism also involves an attitude of self-development of individuals with a strong sense of mission in their work, and who seek to integrate life and work [33]. As a result, bohemianism gives rise to a new culture and 
lifestyle that integrate traditionalism and rationalism, display artistic creativity and are comfortable with the rapid advances in fashion and technology [1].

The bohemian scene approach of cultural policy is an integral strategy that incorporates production and consumption factors, drawing from both the city as a "cultural scene" and the creative city approach. Specifically, the creative city approach represents a production and development-oriented strategy that takes culture as an instrument of economic growth. Its core is to attract cultural and creative talents and enterprises, construct cultural and creative industries and stimulate employment and economic growth [16]. On the other hand, the city as a cultural scene approach centers on cultural consumption, promoting amenities and activities that enhance cultural participation of diverse social groups as well as generating economic growth. The bohemian cultural scene approach draws from both, emphasizing creative development and innovation as well as cultural consumption. It seeks to attract creative elements, such as artists, young professionals, entrepreneurs and startup firms via vibrant and unconventional bohemian cultural scenes. The concentration of these creative elements strengthens the level of bohemianism and the effect of the scene, further driving incoming and local participants to engage in cultural consumption with creative characteristics. This creates a spillover cultural effect that attracts and inspires more creative talents and enterprises [34,35], stimulating local economic regeneration and development incrementally [36,37]. Lloyd documented how Chicago's Wicker Park, as a center of artistic and cultural production, gathered a large number of young bohemian artists and enterprises, providing human capital crucial for the region's economic revival as well as driving cultural and creative consumption [35]. The bohemian scene also gives rise to a lively, stimulating and creative lifestyle through street activities, cafe culture, music, etc. [10].

It can be seen that the bohemian scene integrates land, technology, capital, human capital, local esthetics and cultural consumption, and that creative subjects are attracted to cities with a vibrant bohemian scene. First of all, creative talents prefer local street culture composed of small commercial amenities, such as coffee shops, street artists, galleries and pubs. They are consumers and participants of the scene, but are its producers simultaneously. The bohemian scene encourages self-expression and unconventional ideas, enabling individuals to creatively participate in both consumption and production activities. Second, creative talents and enterprises require spaces for social gathering and brainstorming. In the bohemian scene, a diverse set of amenities, such as cafes and bookstores, provide spaces to find like-minded people and exchange ideas [1].

Therefore, this paper poses the Hypothesis H1 that bohemian scene significantly increases urban creative development. Specifically:

Hypothesis 1a (H1a). Bohemian scene as a whole significantly increases urban creative development score.

Hypothesis $\mathbf{1 b}$ (H1b). Subdimensions of bohemian scene significantly increase urban creative development score.

The bohemian scene is operationalized into bohemian amenities. Florida once proposed a bohemian index to measure a city's acceptance of bohemianism. The bohemian index uses census data to count the number of writers, designers, artists and other groups, that is, it operationalizes bohemian scenes through the amount of human capital within a city [1]. Compared with the footloose nature of human capital, amenities are the foundational components of bohemian scenes, as operationalization through human capital does not account for the qualities of urban spaces and the activities within, or the experiential, personalized and fragmented forms of production and consumption that increasingly take place in the post-industrial city. This kind of post-industrial production and consumption is inseparable from the amenities within an urban space. Urban creativity research needs to pay attention to the creative context of the city, combining creative culture, creative urban space and creative people. The bohemian scene combines the diverse creative talents and 
cultures in the city, as well as the popular bohemian facilities in the city where they live. Therefore, this study uses bohemian amenities as a measure of bohemian scenes. Based on the above point of view, Silver and Clark operationalize the bohemian scene into amenities such as comedy theaters, rap restaurants and karaoke halls, based on data from Canada and the US [17]. A similar measure of bohemianism is adopted by Jeong and Joeng and Patterson $[32,38]$. However, there is no empirical research on bohemian scenes to date in China. Thus, in order to construct the Chinese bohemian scene, we need to draw on Silver and Clark as well as adjusting according to cultural and consumption activities in the Chinese context.

\section{Methods and Design}

\subsection{Sample City Selection}

Cities were selected based on population size and economic aggregate, using data from the 2018 China Statistical Yearbook and China Urban Statistical Yearbook. The first step was to select cites according to the permanent urban population. To a certain extent, the population of a city reflects the result of the flow of labor factors under market mechanisms [39]. In addition, the main administrative unit of Chinese cities- "wide area city" -includes not only urban areas but also vast suburban counties. Thus, in order to be consistent with domestic and international research designs, this paper selected cities with a permanent urban area population of more than 1 million. The second step was to select cities according to the economic aggregate. The development of creative cities requires geographic scale and industrial foundation, and not all cities are suitable for it [6]. The development of innovation and creativity in a city requires a certain economic scale and level of development. Therefore, this paper selected cities with a GDP of more than 100 billion yuan. Based on these two aspects, 65 cities were eventually selected. The names and geographic locations of these cities are shown in Table 1.

Table 1. Names and geographic locations of sample cities.

\begin{tabular}{|c|c|c|}
\hline & Western Cities & Eastern Cities \\
\hline Northern Cities & $\begin{array}{c}\text { Baotou, Changchun, Daqing, Harbin, } \\
\text { Hohhot, Jilin, Lanzhou, Luoyang, } \\
\text { Taiyuan, Urumqi, Xi'an, } \\
\text { Yinchuan, Zhengzhou }\end{array}$ & $\begin{array}{l}\text { Baoding, Beijing, Dalian, Handan, } \\
\text { Jinan, Jining, Linyi, Qingdao, } \\
\text { Shenyang, Shijiazhuang, Tangshan, } \\
\text { Tianjin Weifang, Xuzhou, Yantai, Zibo }\end{array}$ \\
\hline Southern Cities & $\begin{array}{l}\text { Changsha, Chengdu, Chongqing, } \\
\text { Guiyang, Hefei, Kunming, Liuzhou, } \\
\text { Nanchang, Nanning, Wuhan, Wuhu, } \\
\text { Xiangyang, Zhuzhou, Zunyi }\end{array}$ & $\begin{array}{c}\text { Changzhou, Foshan, Fuzhou, } \\
\text { Guangzhou, Haikou, Hangzhou, } \\
\text { Huai'an, Huizhou, Nanjing, Nantong, } \\
\text { Ningbo, Quanzhou, Shanghai, } \\
\text { Shantou, Shaoxing, Shenzhen, } \\
\text { Suzhou, Wenzhou, Wuxi, Xiamen, } \\
\text { Yancheng, Yangzhou }\end{array}$ \\
\hline
\end{tabular}

\subsection{Independent Variables}

Control variables were traditional factors of urban creative development in China, including GDP, the proportion of the tertiary industry in GDP, GDP per capita, the number of students enrolled in colleges and universities, southern/northern cities and eastern/western cities. The data for variables were obtained from China Statistical Yearbook and China Urban Statistical Yearbook in 2018. In order to reduce heteroscedasticity, a logarithmic transformation was performed on all continuous variables.

This paper measured the bohemian scene of a city using the number of cultural amenities that reflect bohemianism. Since bohemian scenes are consumption-oriented, and the main source of consumption information in China is the Internet as well as social media, this paper obtained amenities data from Dianping.com (http:/ / www.dianping.com/, accessed on 30 November 2019), the most representative and comprehensive consumption and comment-based social media platform. According to past studies [17] and the classifica- 
tion of amenities in Dianping.com, the bohemian scene is operationalized into 27 bohemian cultural amenities, as shown in Table 2. These amenities are considered to reflect values of bohemian scenes based on their descriptions and user comments on Dianping.com.

Table 2. Bohemian cultural amenities selected from Dianping.com.

\begin{tabular}{cc}
\hline No. & Bohemian Cultural Amenities \\
\hline 1 & Board games \\
2 & Locked room escape \\
3 & Bars \\
4 & Live performances \\
5 & Party house \\
6 & Cafe \\
7 & Video game halls \\
8 & Cinemas \\
9 & Graffiti \\
10 & Rock climbing \\
11 & DIY workshops \\
12 & Tattoo parlors \\
13 & Recording studios \\
14 & Theaters \\
15 & KTVs \\
16 & Bookstores \\
17 & Custom tailored clothes \\
18 & Combative sports \\
19 & Custom furniture \\
20 & Galleries \\
21 & Hair salons \\
22 & Photo studios \\
23 & Internet cafes \\
24 & Medical cosmetology \\
25 & Fxhibitions \\
26 & Floriculture \\
27 & Manicure and eyelash salons \\
\hline &
\end{tabular}

Factor analysis was conducted using the number of bohemian amenities (27 types) in each city. The results indicate that the information extraction ratios contained in the 27 variables were all higher than $70 \%$, and the Kaiser-Meyer-Olkin (KMO) measure of sampling adequacy was 0.950 . The approximate chi-square of the Bartlett's test of sphericity was 3101.055, which indicates the test result is significant, and the null hypothesis is rejected. There is a strong correlation between the number of 27 types of bohemian cultural facilities. Using the varimax-rotation method, the bohemian scene is composed of two principal components after dimension reduction. The cumulative percentage of variance is $85.767 \%$, which indicates that these two principal components are sufficient to construct an urban bohemian scene; the extraction sums of squared loadings variance of the first principal component is $45.265 \%$, the extraction sums of squared loadings variance of the second principal component is $40.502 \%$. Thus, we obtained the bohemian scene scores of 65 major Chinese cities:

$$
F_{\text {BohemiansceneScore }}=\frac{P v c r_{1} * Z F_{1}+P v c r_{2} * Z F_{2}}{\sum_{i=1}^{k} P v c r_{k}} k \leq 2
$$

In Formula (1), $P v c r_{k}$ stands for the variance contribution rate of common factor $k$, $Z F_{k}$ stands for the standardized factor score of the sample on the common factor $k$

$$
F_{\text {BohemiansceneScore }}=\frac{45.265 \% * Z F_{1}+40.502 \% * Z F_{2}}{45.265 \%+40.502 \%}
$$


The scores of the amenities in the two principal components were examined. Under the first principal component, "board game", "escape from the locked room", "bar", "performance" scored higher. The activities involved in these amenities are considered to embody qualities of "self-expression" - improvisation, responding to situations in unscripted ways and bringing one's own unique perspectives. Thus, the first principal component is named "self-expression" [17]. Under the second principal component, amenities such as "bookstore", "custom clothing", "fighting", "galleries" received higher scores. The activities involved in these amenities are considered to embody qualities of "charisma", as they possess extraordinary spiritual qualities that attract and compel others to follow [17]. Thus, the second principal component is named "charisma".

The bohemian cultural scene in Chinese cities was operationalized into two dimensions: "self-expression" and "charisma". The standardized scores in these two dimensions of each city were taken as the key independent variables of this study (see Appendix A). The bohemian scene consisted of two dimensions, as a result of factor analysis using mainstream Chinese cultural consumption amenities data, resonating with Silver and Clark, "a scene is more Bohemian if it exhibits resistance to tradition, affirms individual selfexpression, eschews utilitarianism, values charisma" [17]. To a certain extent, this indicates that bohemian scenes similarly exist in China, and that this research could contribute to international comparative research.

\subsection{Dependent Variables}

The operationalization of dependent variables combined traditional technology and creative talents. The dependent variable of this study was urban creative development/ innovation. Combining China's developmental context and research feasibility, the creative development level of a city can be operationalized into two dimensions- the number of patents and creative talents. Accordingly, urban creative development is measured by five variables: "number of patent applications", "number of granted patents", "cultural, sports and entertainment industry", "scientific research, technical services and geological prospecting industry", "information transmission, computer services and software industry".

"Urban creative development score" was used as the dependent variable in this study. Exploratory factor analysis was performed on the above five variables to obtain the city's creative development score. The extraction ratios contained in the five variables all exceeded $65 \%$, so the extracted common factors can explain the variables relatively well. A KMO measure of sampling adequacy was 0.747 , which suggests the information overlap between the variables is acceptable, and a satisfactory factor analysis model can be obtained. The approximate chi-square of the Bartlett's test of sphericity was 492.672, which indicates the results are significant and the null hypothesis is rejected. The five variables of urban creative development have a strong correlation. Using the varimax rotation method, the five variables were transformed into one principal component, with a cumulative percentage of variance of $76.72 \%$. Thus, this principal component was sufficient to construct an evaluation index for urban creative development. A function of urban creative development can be constructed through weighting. According to regression, the standardized scores of creative development level of 65 major cities in China can be obtained to measure their respective creative development (see Appendix B).

$$
Z F_{\text {Urban Creative Development }}=\sum_{i=1}^{k}\left(F L_{k} * Z \ln x_{k}\right) k \leq 5
$$

In Formula (3), $F L_{k}$ stands for the loading of urban development level factor on variable $\mathrm{K}, Z \ln x_{k}$ stands for the standardized score of the natural logarithm of the sample in the mean value of the variable $K$. 


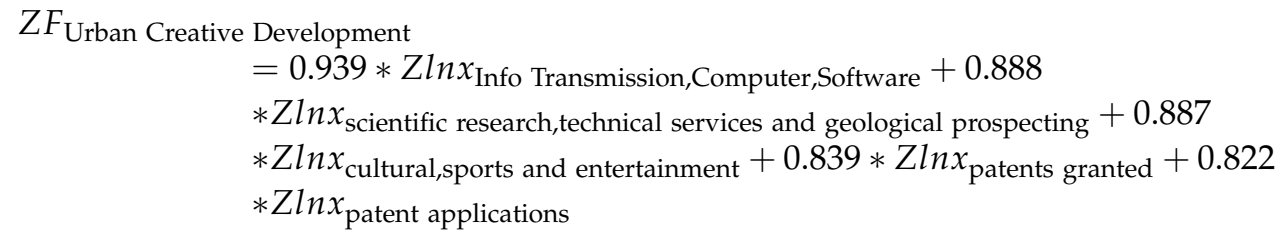

\section{Results}

\subsection{Creative Development of Major Chinese Cities}

There are significant differences in the creative development of major cities in China. Top-echelon cities, such as Beijing, have a strong leading position, while most other cities lag. According to two-step cluster analysis and the Bayesian information criterion, the creative development level of 65 major cities can be divided into three tiers. As shown in Figure 1, the first echelon (high) includes 11 cities: Beijing, Shanghai, Chengdu, Shenzhen, Guangzhou, Hangzhou, Nanjing, Tianjin, Xi'an, Chongqing, Wuhan, etc.; the second echelon (middle) includes 22 cities: Zhengzhou, Jinan, Hefei, etc.; the third echelon includes 32 cities: Wenzhou, Yangzhou, Nantong etc.

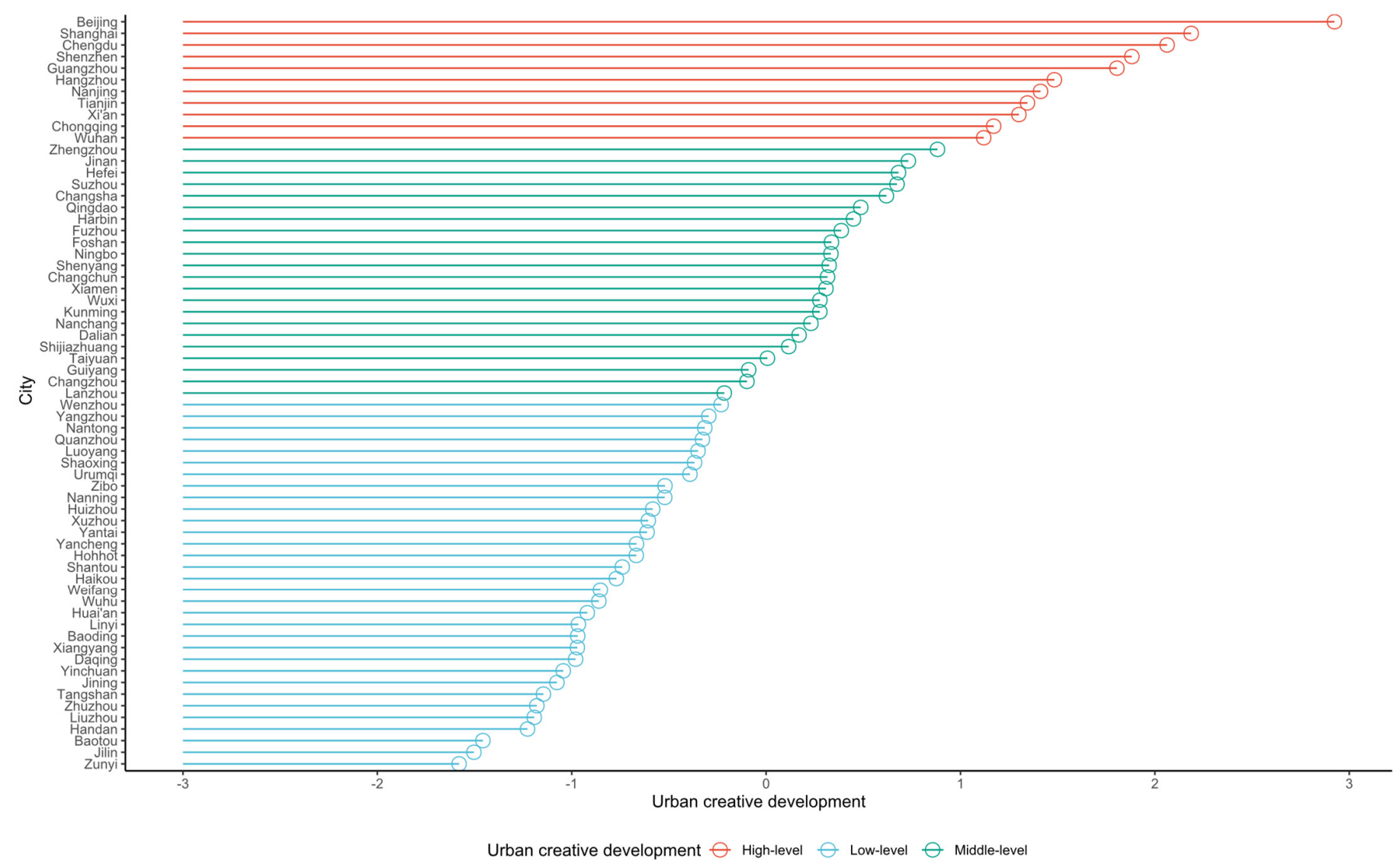

Figure 1. Creative development level of major Chinese cities can be divided into three echelons based on cluster analysis.

\subsection{Bohemian Scene as New Driver of Urban Creative Development}

There is a linear and positive correlation between bohemian scenes and urban creative development. As shown in Figure 2, for all the major cities in China, the bohemian scene score is positively correlated with the level of urban creativity. Table 3 and Figures 3-5 present correlations for specific dimensions (bohemian scene score, self-expression and charisma) in different Chinese regions. First, the correlation between the bohemian scene (bohemian score, self-expression and charisma) and urban creative development is stronger in southern cities than northern cities. Second, the correlation between self-expression 
and urban creative development in eastern cities is stronger than that in western cities, whereas the correlation between charisma and urban creative development in western cities is higher than that in eastern cities. However, these are preliminary conclusions, and the specific effects need to be verified using regression model.

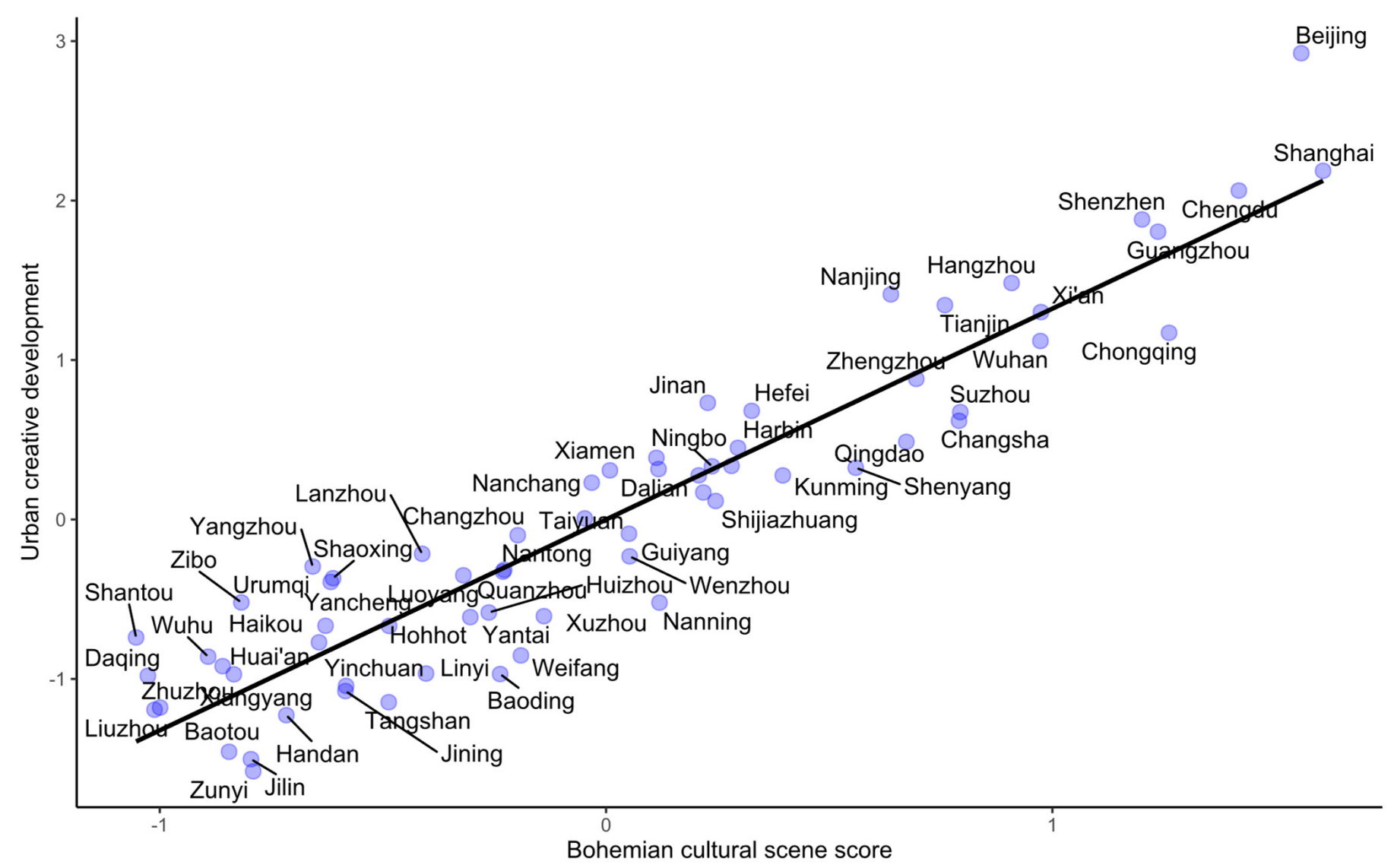

Figure 2. Scatterplot of bohemian scene score and urban creative development level.

Table 3. Spearman correlation between the subdimensions of urban bohemian scenes and the level of urban creativity in different regions.

\begin{tabular}{cccc}
\hline & $\begin{array}{c}\text { Bohemian Scene } \\
\text { Score and Creative } \\
\text { Development }\end{array}$ & $\begin{array}{c}\text { Self-Expression } \\
\text { Dimension and } \\
\text { Creative Development }\end{array}$ & $\begin{array}{c}\text { Charisma Dimension } \\
\text { and Creative } \\
\text { Development }\end{array}$ \\
\hline Eastern Cities & $0.887^{* * *}$ & $0.866^{* * *}$ & $0.357^{*}$ \\
Western Cities & $0.919^{* * *}$ & $0.693^{* * *}$ & $0.784^{* * *}$ \\
Southern Cities & $0.946^{* * *}$ & $0.762^{* * *}$ & $0.746^{* * *}$ \\
Northern Cities & $0.882^{* * *}$ & $0.625^{* * *}$ & 0.353 \\
\hline Note: ${ }^{*} p<0.05^{* * *} p<0.001$. & &
\end{tabular}



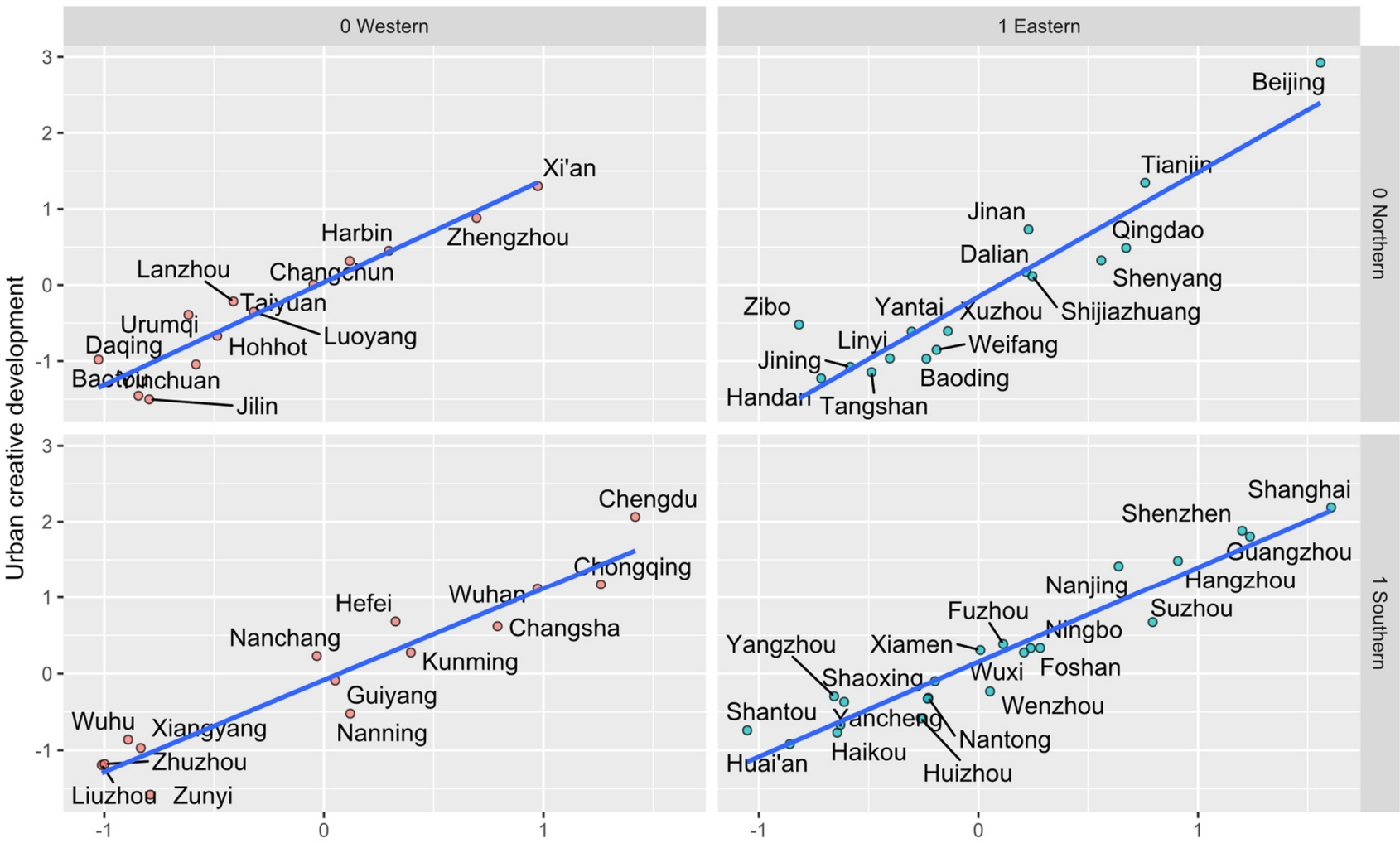

Bohemian scene score

Figure 3. Scatterplot of bohemian scene score and urban creativity score in different regions.

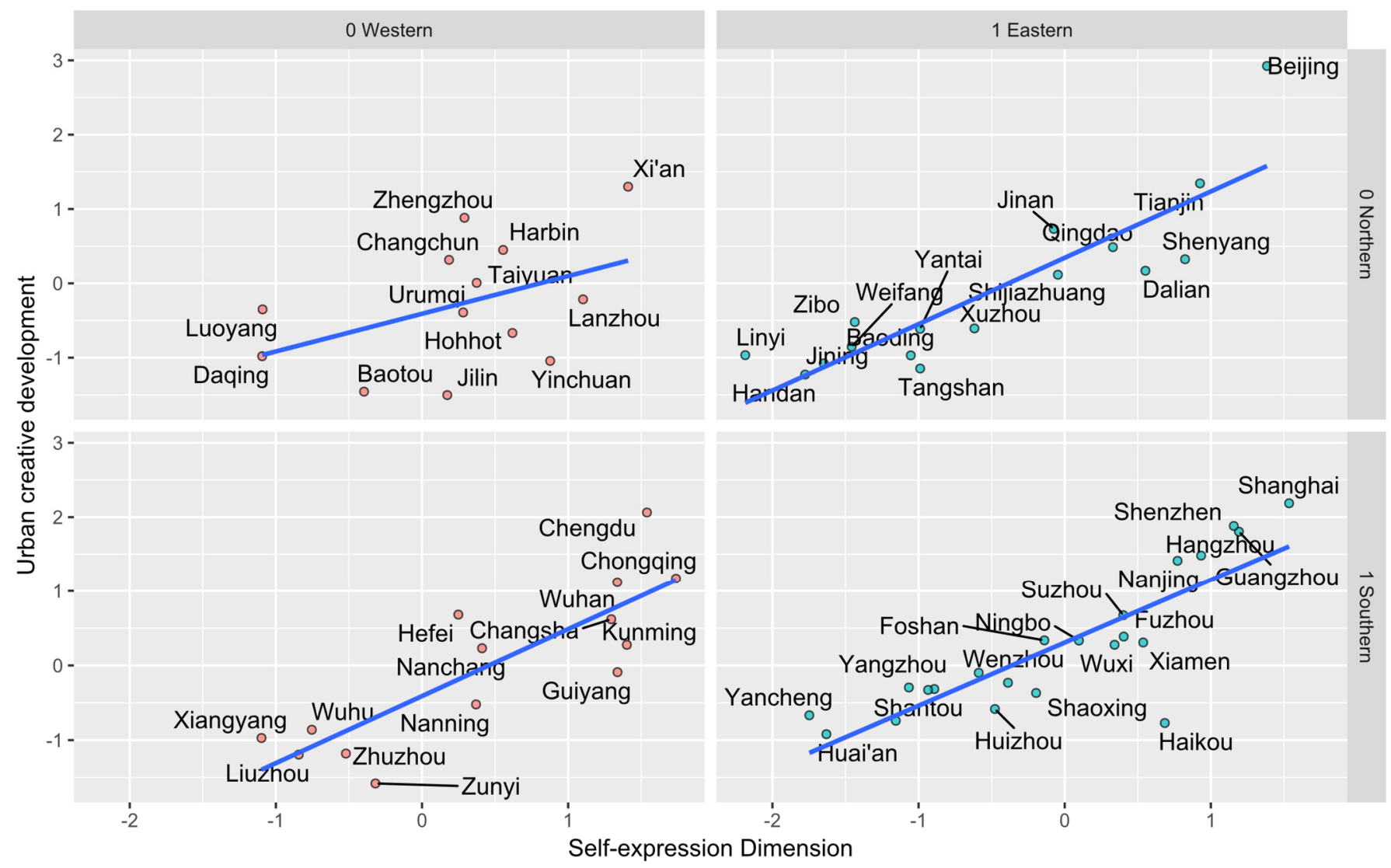

Figure 4. Scatterplot of self-expression dimension and urban creativity score in different regions. 


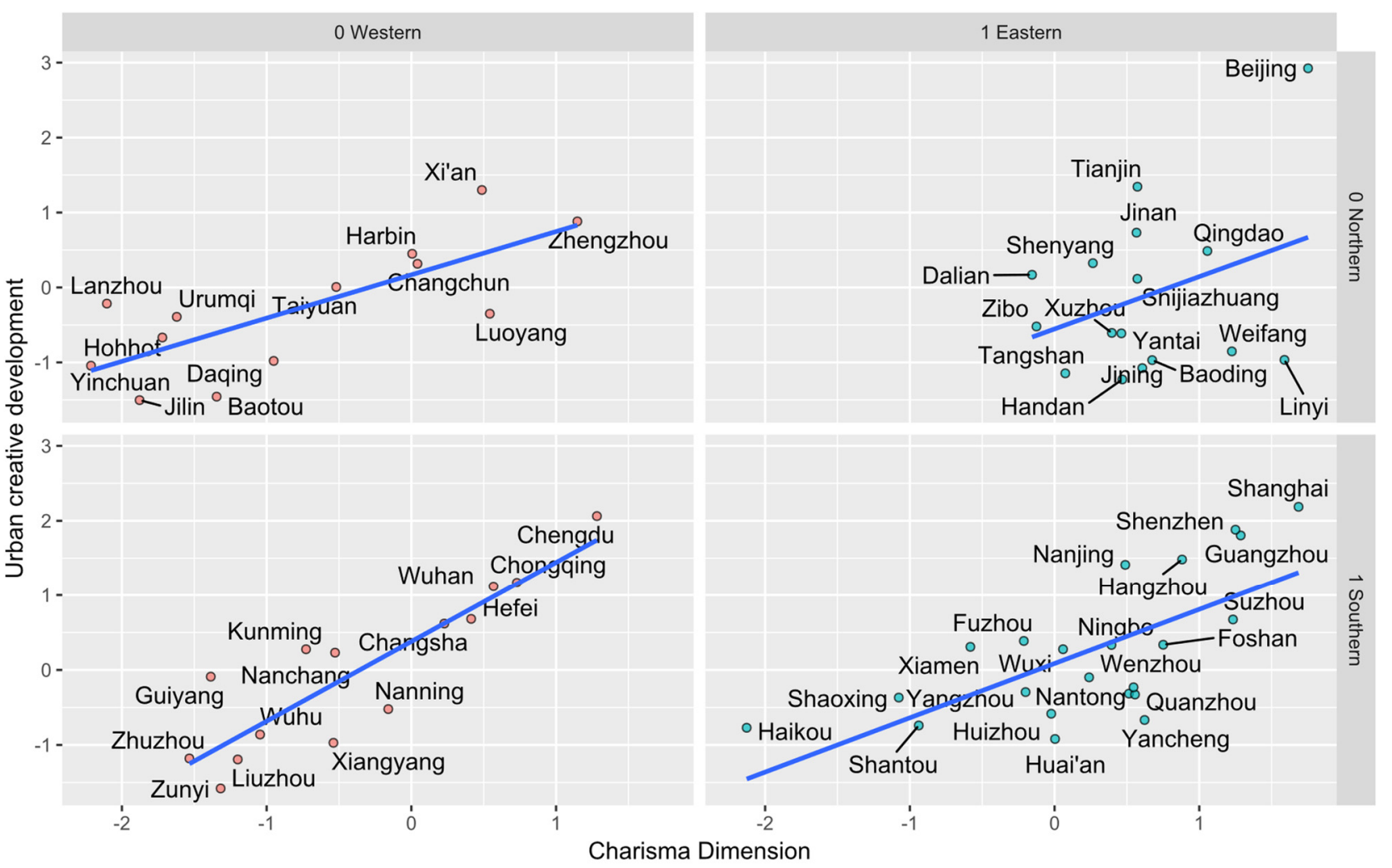

Figure 5. Scatterplot of charisma dimension and urban creativity score in different regions.

Before regression analysis, tree-based model is used for initial exploration. In this study, tree-based model of CRT growing algorithm is used for analysis. This analysis method overcomes the omission of high-order terms and interaction terms of independent variables. Moreover, the tree-based model algorithm is a non-parametric method without too many restrictions on applicable conditions. The tree-based model of this study takes the three ordinal variables of echelons of urban creative development as the dependent variable. According to the previous clustering analysis results, echelons of urban creative development are divided into three clusters: high, middle and low; maximum tree depth is set to 5 , minimum cases in parent node and minimum cases in child node are set to 1 . Based on Gini index (Formulas (5)-(7)), the tree model was used to predict the echelons of urban creative development through growing and pruning. The final tree model includes the standardized $(Z)$ bohemian scene score, GDP (in ten thousand Yuan), enrollment in groups and universities, proportion of tertiary industry in GDP (\%), per capital GDP (yuan) and southern cities, as shown in Figure 6. There are 15 nodes, 8 terminal nodes and tree depth of 5 . The estimated risk of cross validation is 0.154 , with a standard of error of 0.045 . The overall prediction accuracy of tree model is $98.5 \%$ - the prediction effect is satisfactory. For any node $t$ in the tree, the Gini index $g(t)$ is calculated as follows:

$$
g(t)=\sum_{j \neq i} p(j \mid t) p(i \mid t)
$$

When split method (S) is used to divide the original node T into sub nodes, $\alpha$ and $\beta$, the corresponding change in Gini index is:

$$
\Phi(s, t)=g(t)-p_{\alpha} g\left(t_{\alpha}\right)-p_{\beta} g\left(t_{\beta}\right)
$$


In Formula (6), $p_{\alpha}$ and $p_{\beta}$ represent the proportion of the two sub nodes in which the sample is split. The best splitting method is to maximize the change of Gini index. In Formula (7), $\Omega$ is the set of all possible zero values.

$$
\varphi\left(s^{*}, t\right)=\max _{s \in \Omega} \Phi(s, t)
$$

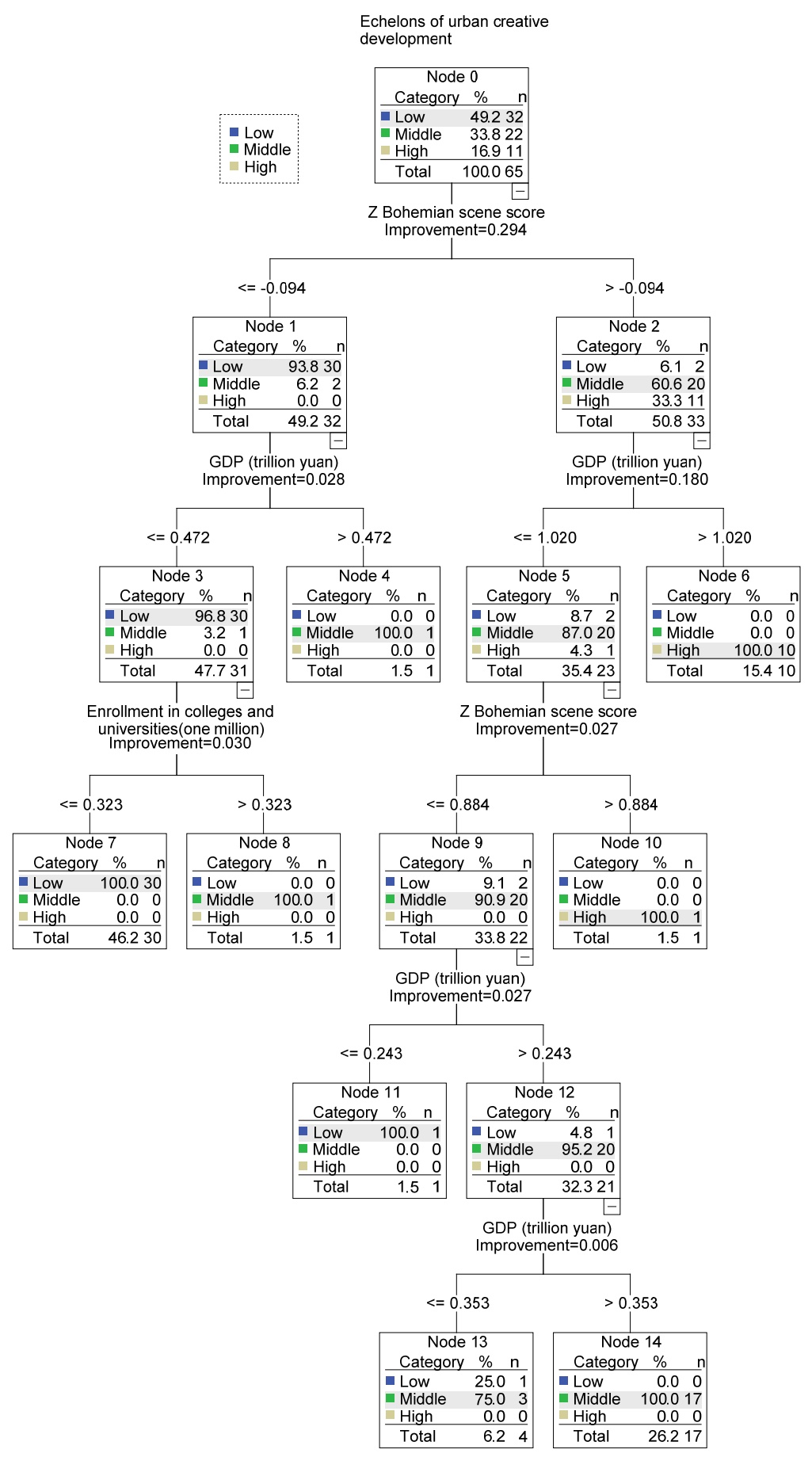

Figure 6. Tree-based model results affecting echelons of urban creative development.

After running a tree model with CRT growth algorithm, the importance of the factors affecting the development of urban creativity is obtained, as indicated by the results of the normal Gini index. As shown in Figure 7, the ranking of the importance of the factors affecting the development of urban creativity from high to low is: the total urban GDP, $\mathrm{Z}$ 
bohemian scene, enrollment in colleges and universities, proportion of tertiary industry in GDP (\%), per capita GDP (yuan) and southern cities.

Results from the tree-based model indicate that the bohemian scene of the city has an important impact on the level of creative development, ranking second among the independent variables. Only $6.1 \%$ of the cities with a Z bohemian scene score higher than 0.094 have a low level of urban creative development, while $93.8 \%$ of the cities with a $Z$ bohemian scene score of less than or equal to -0.094 have low level of urban creative development. For cities with Z bohemian scene higher than -0.094, if their GDP is higher than RMB 10,000 trillion, then $100 \%$ of them have a high level of creative development, while for cities with a $\mathrm{Z}$ bohemian scene score of less than or equal to RMB 10,000 trillion, only $4.3 \%$ of them are at high creative development level. After a preliminary investigation, whether a city is located in eastern China is not an important factor affecting urban creative development, but whether it is located in southern China is an important factor affecting urban creative development. This shows that different regions may have different effects on the development of urban creativity, which cannot be explained in detail by this tree-based model. It needs to be further explored through multiple regression models.

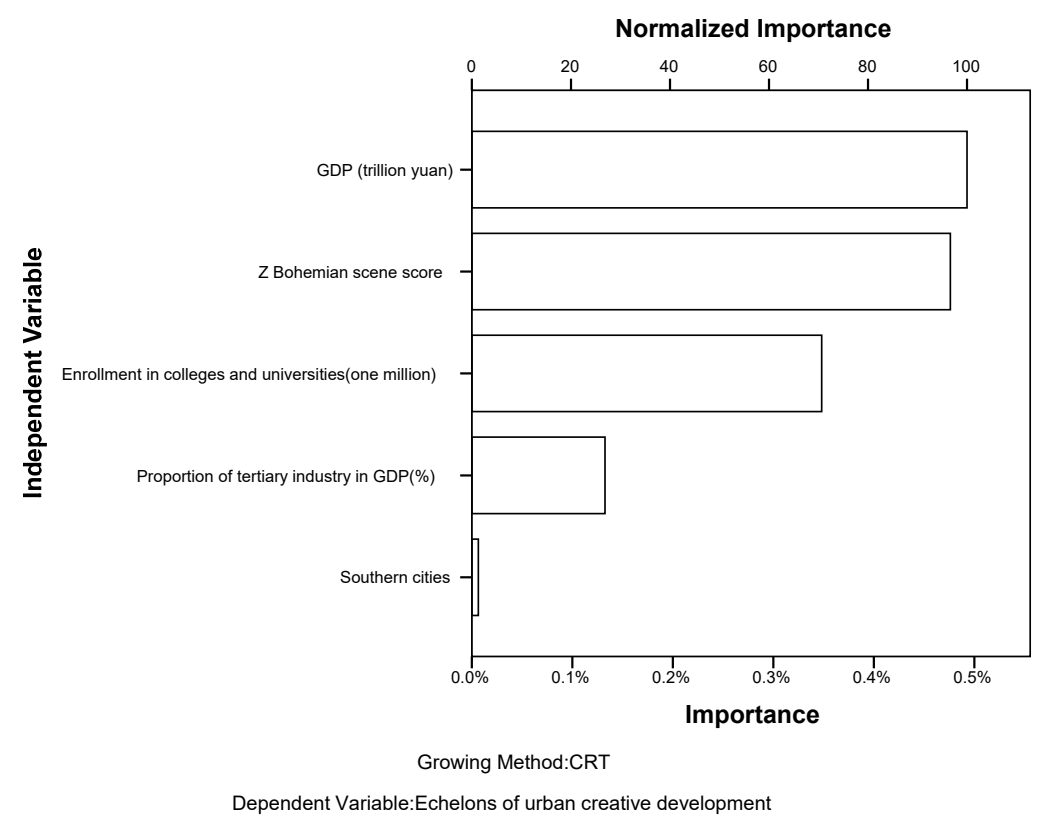

Figure 7. Importance of independent variables measured by Gini index.

The continuous variable " $Z$ creative development" is used as a dependent variable in regression models for further investigation. Regression results are presented in Table 4. While controlling for other variables, bohemian scenes promote the development of urban creativity. In Model 1, which only includes traditional policy factors, GDP (ln), the proportion of tertiary industry in GDP $(\ln )$ and the number of students enrolled in colleges and universities $(\mathrm{ln})$ have a significant $(\mathrm{sig}<0.05)$ and positive effect on urban creativity, controlling for other variables. This suggests that the classical economic and educational urban policy could promote the development of urban creativity. Model 2 adds the bohemian scenes score. Controlling for traditional variables, bohemian scene scores significantly (sig < 0.05) enhance the creative development of China's major cities; GDP and the proportion of tertiary industry in GDP still have significant effect on the creative development of major Chinese cities; however, the number of students enrolled in colleges and universities no longer significantly impacts the level of creative development. In model 2 , after a collinearity test, the vif values of each variable are less than 10 , indicating there is no collinearity issue in this model. The heteroscedasticity (hettest) test yields a $\mathrm{chi}^{2}$ value of 2.65 (prob $>c h i^{2}=0.1033<0.05$ ). Therefore, the null hypothesis is rejected, and there is no issue of heteroscedasticity in this model. 
In order to account for the differences in the impact of the two dimensions of bohemian scene on the creative development of major cities, Model 3 adds the two dimensions of bohemian scene. Controlling for other variables, self-expression, charisma, GDP and the proportion of tertiary industry in GDP all significantly (sig < 0.05 ) promote urban creativity. For all major Chinese cities, the charisma dimension has a stronger effect in promoting urban creativity than the self-expression dimension; the traditional growth-oriented urban policy is the cornerstone of promoting the construction of bohemian scene, while education does not significantly promote urban creativity. Since only major Chinese cities are selected into the sample and analyzed, there is a certain level of truncation. Therefore, for Model 4, a truncated regression is applied to the variables of Model 3, generating similar results as Model 3. Therefore, the above conclusions are relatively robust.

In order to account for the differences in the influence of the bohemian scene and its dimensions among different regions of China, Model 5 and Model 6 consider the regional differences between cities in southern and northern China. Model 5 only includes major cities in southern China. The results indicate that self-expression, charisma and regional GDP (ln) significantly (sig < 0.05) promote the creative development of cities in southern China; further, self-expression is found to have a stronger impact on the creative development of southern cities than charisma. Similarly, Model 6 includes major cities in northern China, and finds that charisma and regional GDP significantly $(\operatorname{sig}<0.05)$ promote the creative development of major cities in northern China, but the effect of self-expression is not significant.

Model 7 and Model 8 consider the regional differences between eastern and western cities in China. Model 7 only includes the eastern coastal cities of China. Since the heteroscedasticity (hettest) test of Model 7 is significant (sig $<0.05$ ), Model 7 adopts robust OLS regression. The results of Model 7 indicate, controlling for other variables, that charisma, regional GDP $(\ln )$, the proportion of tertiary industry in GDP $(\ln )$, being located at the southeast coast of China, all significantly promote urban creative development $($ sig $<0.05)$, while the effect of the self-expression dimension is not significant. Model 8 only includes cities in western China, and finds that both self-expression and charisma significantly promote $(\mathrm{sig}<0.05)$ the creative development of cities, while the effect of regional GDP $(\ln )$ is not significant.

Table 4. Regression analysis results of factors influencing urban creativity.

\begin{tabular}{|c|c|c|c|c|c|c|c|c|}
\hline & \multicolumn{2}{|c|}{$\begin{array}{l}\text { Model } 1 \\
\text { (OLS) }\end{array}$} & \multicolumn{2}{|c|}{$\begin{array}{l}\text { Model } 2 \\
\text { (OLS) }\end{array}$} & \multicolumn{2}{|c|}{$\begin{array}{l}\text { Model } 3 \\
\text { (OLS) }\end{array}$} & \multicolumn{2}{|c|}{$\begin{array}{c}\text { Model } 4 \\
\text { (Truncated Regression) }\end{array}$} \\
\hline & B & SE & B & SE & B & SE & B & SE \\
\hline Z Bohemian scene score & & & $0.577^{* * *}$ & 0.144 & & & & \\
\hline $\begin{array}{l}\text { Z Self-expression } \\
\text { dimension }\end{array}$ & & & & & $0.236^{* * *}$ & 0.100 & $0.232 *$ & 0.145 \\
\hline Z Charisma dimension & & & & & $0.290 * * *$ & 0.070 & $0.291^{* * *}$ & 0.067 \\
\hline $\ln$ GDP & $0.920 * * *$ & 0.078 & $0.580^{* * *}$ & 0.109 & $0.608^{* * *}$ & 0.112 & $0.608^{* * *}$ & 0.109 \\
\hline $\begin{array}{l}\text { ln proportion of tertiary } \\
\text { industry in GDP }\end{array}$ & $0.864^{* *}$ & 0.250 & $0.677^{* *}$ & 0.227 & $0.868^{* *}$ & 0.289 & $0.890 * *$ & 0.280 \\
\hline $\begin{array}{l}\text { ln enrollment in colleges } \\
\text { and universities }\end{array}$ & $0.186^{* *}$ & 0.065 & 0.042 & 0.068 & 0.048 & 0.069 & 0.059 & 0.067 \\
\hline ln per capita GDP & -0.144 & 0.140 & 0.006 & 0.130 & -0.001 & 0.130 & -0.002 & 0.130 \\
\hline Southern cities & $0.176^{*}$ & 0.083 & 0.122 & 0.075 & 0.151 & 0.079 & $0.156^{*}$ & 0.078 \\
\hline Eastern cities & 0.062 & 0.091 & 0.005 & 0.082 & -0.053 & 0.989 & -0.041 & 0.095 \\
\hline Constant & $-20.277^{* * *}$ & 1.553 & $-23.493 * * *$ & 2.184 & $-14.727^{* * *}$ & 2.469 & $-14.946^{* * *}$ & 2.385 \\
\hline $\mathrm{N}$ & \multicolumn{2}{|c|}{65} & \multicolumn{2}{|c|}{65} & \multicolumn{2}{|c|}{65} & \multicolumn{2}{|c|}{65} \\
\hline $\mathrm{F}$ & \multicolumn{2}{|c|}{$101.53^{* * *}$} & \multicolumn{2}{|c|}{$111.99 * * *$} & \multicolumn{2}{|c|}{$98.38^{* * *}$} & & \\
\hline$c h i^{2}$ & & & & & & & 833. & \\
\hline$R^{2}$ & \multicolumn{2}{|c|}{0.913} & \multicolumn{2}{|c|}{0.932} & \multicolumn{2}{|c|}{0.934} & & \\
\hline Adj- $R^{2}$ & \multicolumn{2}{|c|}{0.904} & \multicolumn{2}{|c|}{0.924} & \multicolumn{2}{|c|}{0.924} & & \\
\hline
\end{tabular}


Table 4. Cont.

\begin{tabular}{|c|c|c|c|c|c|c|c|c|}
\hline & \multicolumn{2}{|c|}{$\begin{array}{c}\text { Model } 5 \\
\text { (Southern Cities OLS) }\end{array}$} & \multicolumn{2}{|c|}{$\begin{array}{c}\text { Model } 6 \\
\text { (Northern Cities OLS) }\end{array}$} & \multicolumn{2}{|c|}{$\begin{array}{c}\text { Model } 7 \\
\text { (Eastern Cities OLS) }\end{array}$} & \multicolumn{2}{|c|}{$\begin{array}{c}\text { Model } 8 \\
\text { (Western Cities OLS) }\end{array}$} \\
\hline & B & SE & B & SE & B & SE & B & SE \\
\hline \multicolumn{9}{|l|}{ Z Bohemian scene score } \\
\hline $\begin{array}{l}\text { Z Self-expression } \\
\text { dimension }\end{array}$ & 0.318 * & 0.129 & 0.194 & 0.153 & 0.180 & 0.093 & $0.436^{*}$ & 0.180 \\
\hline Z Charisma dimension & $0.292 * *$ & 0.094 & $0.297 *$ & 0.108 & $0.220 * *$ & 0.070 & $0.477^{* *}$ & 0.128 \\
\hline $\ln \mathrm{GDP}$ & $0.453 * *$ & 0.140 & $0.824^{* * *}$ & 0.179 & $0.700^{* * *}$ & 0.126 & 0.023 & 0.243 \\
\hline $\begin{array}{l}\text { In proportion of tertiary } \\
\text { industry in GDP }\end{array}$ & 0.374 & 0.485 & 0.741 & 0.363 & $1.154^{* *}$ & 0.405 & -0.508 & 0.567 \\
\hline $\begin{array}{l}\text { ln enrollment in colleges } \\
\text { and universities }\end{array}$ & 0.061 & 0.085 & 0.089 & 0.131 & 0.021 & 0.080 & 0.299 & 0.144 \\
\hline ln per capita GDP & 0.144 & 0.173 & -0.262 & 0.216 & -0.089 & 0.122 & 0.202 & 0.243 \\
\hline Southern cities & & & & & $0.219 *$ & 0.119 & -0.169 & 0.141 \\
\hline Eastern cities & 0.137 & 0.157 & 0.062 & 0.141 & & & & \\
\hline Constant & $-11.848^{* *}$ & 3.579 & $-15.334^{* * *}$ & 3.456 & $-16.217^{* * *}$ & 2.667 & -4.332 & 5.391 \\
\hline $\mathrm{N}$ & \multicolumn{2}{|c|}{36} & \multicolumn{2}{|c|}{65} & \multicolumn{2}{|c|}{29} & \multicolumn{2}{|c|}{38} \\
\hline $\mathrm{F}$ & \multicolumn{2}{|c|}{$69.88^{* * *}$} & \multicolumn{2}{|c|}{$98.38^{* * *}$} & \multicolumn{2}{|c|}{$56.04^{* * *}$} & \multicolumn{2}{|c|}{$120.58^{* * *}$} \\
\hline \multicolumn{9}{|l|}{$c h i^{2}$} \\
\hline $\mathrm{R}^{2}$ & \multicolumn{2}{|c|}{0.946} & \multicolumn{2}{|c|}{0.934} & \multicolumn{2}{|c|}{0.949} & \multicolumn{2}{|c|}{0.961} \\
\hline Adj- $R^{2}$ & \multicolumn{2}{|c|}{0.932} & \multicolumn{2}{|c|}{0.924} & \multicolumn{2}{|c|}{0.932} & & \\
\hline
\end{tabular}

\section{Conclusions and Discussion}

The bohemian scene is a special type of cultural scene that could drive an integral cultural policy approach between the city as a "cultural scene" and the creative city approach [18]. It is a new driver for urban cultural and creative development. Through an empirical analysis of 65 major Chinese cities, this study finds that the bohemian cultural scene of Chinese cities is mainly composed of two dimensions, "self-expression" and "charisma". The bohemian scene is found to significantly promote the development of urban creativity, which suggests that China's urban development policies need to be changed: First, a developmental policy approach oriented at technological innovation is no longer sufficient facing a new stage of urban development; instead, an integral cultural policy approach oriented toward creative service industries and creative consumption is increasingly required. Second, urban policies need to heed the cultural context attractive to creative talents and creative enterprises.

At the current stage, economic growth is still the basis of bohemian scenes policy in China. For all 65 major cities in China, with bohemian scenes variables included, GDP still significantly promotes the development of urban creativity. Therefore, growth-oriented policies should be a basic component of the bohemian scene policy approach. However, higher education does not significantly promote the development of urban creativity when bohemian scenes variables are included, which suggests that educational policies are less effective at promoting urban creativity than bohemian scenes policy. From the empirical results, as a whole, bohemian scenes significantly promote creative development in China's major cities; specifically, the charisma dimension has a stronger impact on urban creativity than self-expression. In addition, there are significant regional differences, as different dimensions of bohemian scenes have different effects on creativity development in cities of different Chinese regions. For northern cities, charisma significantly promotes the development of urban creativity, while the effect of self-expression is not significant; for southern cities, the self-expression dimension has a stronger effect in promoting the development of urban creativity than charisma; for eastern coastal cities, only the charisma dimension significantly promotes the development of urban creativity; for western cities, both self-expression and charisma significantly promote the development of urban cre- 
ativity, but charisma has a stronger impact. Therefore, the results suggest that cities in northern and eastern China should focus on developing the charisma dimension of bohemian scenes, encouraging creative subjects to loosen their prudent industriousness and practice dynamic experimentalism to break the "iron cage" of creativity; while southern cities should focus on developing the dimension of self-expression, continue to promote tolerance of people from all walks of life, engage in expressive practices, so as to strive for an esthetic life [17]. For western cities, the two dimensions of bohemian scene should be promoted simultaneously.

Development of bohemian cultural scenes demands an integral policy approach. Firstly, the bohemian scene approach includes both production and cultural consumption aspects. There is an agglomeration effect in the production and consumption of creative subjects: they express values through various activities, and further realize creative consumption and reproduction. The lifestyle and values embedded in the bohemian scene enables urban development in the new stage: creative subjects not only possess a strong sense of individuality, but are also professionally driven, willing to pursue a sense of achievement in transforming their creativity into reality. In addition, even though bohemian scenes could promote economic growth by encouraging cultural creative consumption and employment, the implementation of bohemian scenes policy requires a certain level of economic foundation. Judging from the experience of the world's creative hubs, the government's strategic promotion is the most effective means to develop creative industries [40]. Granted, cultural and esthetic intervention cannot replace the material foundation of the city, "If commuting into a city is a lengthy torment, then companies will head for the suburbs, no matter how many cool museums the city has" [10]. A city cannot achieve creative development entirely through the promotion of bohemian culture. Instead, promotion of the bohemian scene needs to be part of an integral urban policy approach, with the active participation of local actors and citizens as well as increased investment in infrastructure from the government.

Secondly, the implementation of bohemian scenes policy needs to adapt to local conditions, combining local economic foundation, cultural context and the involvement of multiple social actors, and must take creativity and innovation as the goal of urban development, to eventually realize "a better life" for Chinese cities. At present, there are significant variations among the creative development of 65 major Chinese cities. The specific dimensions of bohemian cultural scenes have different effects on creative development in different regions, so urban policies need to be guided according to local conditions. China's southwest city of Chengdu has put forward the concept of "cultural scenes city-making", and achieved successes in promoting creative development. Considering the vast regional differences and cultural policy experiences of advanced cities, the policies of major cities in China should follow the following principles: first, the policy decision of any city needs to be based on the existing comparative advantages. For example, Chengdu combines the concept of cultural scenes with its strategic position as a hub city of the "one belt, one road" supply chain to promote creative applications for the "international supply-chain service scenes" [41].

Second, the cultivation of cultural scenes often requires consistent collaboration from the public, private and the third sector, to create an environment conducive to the growth of bohemian amenities and services, and, in turn, to foster cultural consumption with self-expressive and charismatic characteristics [9,42]. More importantly, it is necessary to organically incorporate new amenities into the existing qualities of space and local patterns of cultural consumption and avoid the "one size fits all" approach. The bohemian cultural scenes approach requires a flexible and inclusive policy approach, widely soliciting the opinions of entrepreneurs, civic leaders, citizens and other multiple social subjects to ascertain the existing cultural and esthetic characteristics and political economy of different regions of the city [17]. For instance, Chengdu created the Future Urban Scenes Laboratory that grants funding and policy support for selected enterprises; applicants are evaluated 
based on user experience, whether new products and services are generated and whether new consumption demands are satisfied [43].

Third, cities need to maintain and build upon their own identities and characteristics in the process of creative development. Jacobs argues that excessively imitating and copying the success of other cities will lead to the collapse of diversity and authenticity [44]. A city's excessive branding and marketing makes consumers feel inauthentic, which will lead to the commercialization of bohemian scenes and stifling of creativity; it will also lead to the insistence on imitation, and homogenization of urban structures, lifestyles and cultures $[45,46]$. This is contrary to bohemianism, which emphasizes self-identity and self-expression. Imitation from other cities will only achieve temporary results. Chengdu incorporated its historical "Tianfu culture" to create a multicultural consumption and immersion scene with the theme of "international style and old Chengdu flavor": from gourmet food and leisure to rural tourism, from fashion to traditional art, Chengdu's cultural tourism projects explore modern and creative expressions of Chengdu's profound Tianfu heritage to create a multistructure amenities system, providing young creative individuals with a more fashionable cultural consumption experience, and promoting production and consumption in the scene [47].

Fourth, the city should aim for practicality and moderate success, instead of a temporary sensation [10]. Intensive capital and scale economy will hinder the development of new companies [48]. "Big city diseases" and "big company disease" will become the "iron cage" of creativity. Especially in the post-industrial era, cities should seek small and practical projects rather than gamble on the future of cities with the expensive dice of high investment. The real purpose of investing in cultural amenities is not to develop any specific industry, such as tourism, but to stimulate urban creativity [1]. Therefore, regardless of the specific measures taken to develop bohemian scenes, policymakers should stay true to the original intention of attracting creative talents and promoting the development of urban creativity.

Finally, we suggest three aspects for future research. First, the unit of analysis could be refined to the level of community or neighborhood. Due to increasing urbanization, migration and globalization, cities are growing in both size and diversity. Different communities in the city may present distinct combinations of amenities, social groups and cultures. Therefore, the analysis of cultural scenes should focus on the community rather than the city level. Due to current limited access to community-level data in China, this study focuses on the city level, which is a relatively macro level unit. Second, future research could extend its analysis to 15 scenes subdimensions [17], and other ideal-typical scenes like the bohemian scene. Specifically, to investigate the cultural and esthetic characteristics of a scene and its impact on urban development; in addition, international comparative research could contribute to the localization of scenes dimensions in line with China's special national conditions and shed important light on the different effects of similar scene dimensions in China and the West. Third, future research could consider using scenes theory as a methodology to study a wider range of urban issues and related policy options, including but not limited to attracting tourists and improving the city's soft power through scenes creation, or investigating the relationship between scenes and urban inequality and even urban risk and security.

Author Contributions: Conceptualization, J.W.; methodology, J.W. and H.Z.; software, H.Z.; validation, H.Z. and T.W.; formal analysis, J.W., H.Z. and T.W.; investigation, H.Z.; resources, J.W.; data curation, H.Z.; writing — original draft preparation, J.W., H.Z. and T.W.; writing—review and editing, T.W. and T.N.C.; visualization, H.Z.; supervision, J.W. and T.N.C.; project administration, J.W.; funding acquisition, J.W. All authors have read and agreed to the published version of the manuscript.

Funding: This research was funded by the National Social Science Fund of China, "Research on the Characteristics and Development Trend of Central City Population Aggregation from the Perspective of Circle Structure Theory", grant number 20ARK001.

Institutional Review Board Statement: Not applicable. 
Informed Consent Statement: Not applicable.

Data Availability Statement: Data are available from the corresponding author upon reasonable request.

Acknowledgments: The authors would like to thank Daniel Silver, Cary Wu, Ning Wang, Ji Qi, Bo Chen, Deting Yin, Yuping Hu, Xuemei Wang, Licheng Ying, Linlin Diao, Yongli Jiao, Ling Huang, Xiaohua Zhong, Bichun Zhang. This article is supported by Beijing Population and Society Development Research Center and Beijing Population Institute.

Conflicts of Interest: The authors declare no conflict of interest.

\section{Appendix A}

\begin{tabular}{|c|c|c|c|}
\hline Variables & Factor Variance & Self-Expression Dimension & Charisma Dimension \\
\hline Board games & 0.932 & 0.897 & 0.357 \\
\hline Locked room escape & 0.889 & 0.868 & 0.368 \\
\hline Bars & 0.825 & 0.857 & 0.302 \\
\hline Live performances & 0.940 & 0.842 & 0.480 \\
\hline Party house & 0.830 & 0.797 & 0.443 \\
\hline Cafe & 0.844 & 0.782 & 0.481 \\
\hline Video game halls & 0.870 & 0.779 & 0.514 \\
\hline Cinemas & 0.923 & 0.768 & 0.577 \\
\hline Graffiti & 0.856 & 0.750 & 0.542 \\
\hline Rock climbing & 0.874 & 0.745 & 0.566 \\
\hline DIY workshops & 0.925 & 0.717 & 0.640 \\
\hline Tattoo parlors & 0.729 & 0.714 & 0.638 \\
\hline Recording studios & 0.820 & 0.709 & 0.564 \\
\hline Theaters & 0.773 & 0.681 & 0.556 \\
\hline KTVs & 0.729 & 0.625 & 0.581 \\
\hline Bookstores & 0.895 & 0.204 & 0.924 \\
\hline Custom tailored clothes & 0.847 & 0.396 & 0.831 \\
\hline Combative sports & 0.931 & 0.528 & 0.807 \\
\hline Custom furniture & 0.850 & 0.489 & 0.781 \\
\hline Galleries & 0.826 & 0.472 & 0.777 \\
\hline Hair salons & 0.903 & $0.57 \overline{3}$ & 0.758 \\
\hline Photo studios & 0.844 & 0.543 & 0.741 \\
\hline Manicure and eyelash salons & 0.958 & 0.679 & 0.705 \\
\hline Internet cafes & 0.852 & 0.600 & 0.702 \\
\hline Medical cosmetology & 0.740 & 0.509 & 0.693 \\
\hline Exhibitions & 0.822 & 0.587 & 0.691 \\
\hline Floriculture & 0.741 & 0.540 & 0.670 \\
\hline KMO measure of sampling adequacy & & 0.950 & \\
\hline $\begin{array}{l}\text { The approximate chi-square of the Bartlett's test } \\
\text { of sphericity }\end{array}$ & & $3101.055 * * *$ & \\
\hline Cumulative percentage of variance & & 85.767 & \\
\hline
\end{tabular}

\section{Appendix B}

\begin{tabular}{|c|c|c|}
\hline Variables & Factor Variance & Creative Development Factor \\
\hline $\begin{array}{l}\text { Employment in information transmission, computer services and } \\
\text { software industry }\end{array}$ & 0.882 & 0.939 \\
\hline $\begin{array}{l}\text { Employment in scientific research, technical services and geological } \\
\text { prospecting industry }\end{array}$ & 0.788 & 0.888 \\
\hline Employment in culture, sports and entertainment & 0.787 & 0.887 \\
\hline Number of patents granted & 0.703 & 0.839 \\
\hline Number of patents applied & 0.676 & 0.822 \\
\hline KMO measure of sampling adequacy & \multicolumn{2}{|c|}{0.747} \\
\hline The approximate chi-square of the Bartlett's test of sphericity & \multicolumn{2}{|c|}{$492.672 * * *$} \\
\hline Cumulative percentage of variance & \multicolumn{2}{|c|}{76.72} \\
\hline
\end{tabular}




\section{References}

1. Florida, R.L. The Rise of the Creative Class: And How It's Transforming Work, Leisure, Community and Everyday Life; Basic Books: New York, NY, USA, 2006; ISBN 978-0-465-02476-6.

2. You, J.-S.; Lu, C.; Zheng, H.-A.; Chen, Z. Analysis on the Construction Mode of Innovative Cities-Taking Shanghai and Shenzhen as Examples. China Soft Sci. 2011, 7, 82-92. (In Chinese)

3. Huang, R.; Liang, Q.-J.; Lv, L.-C. The relationship between Urban Population Structure and Innovation: An Empirical Analysis Based on Chinese Cities. Urban Dev. Res. 2014, 9, 84-91. (In Chinese)

4. Fang, C.-L.; Ma, H.-T.; Wang, Z.-B.; Li, G.-D. Comprehensive evaluation and spatial pattern differentiation of China's innovative city construction. Acta Geogr. Sin. 2014, 4. (In Chinese) [CrossRef]

5. He, S.-J.; Wang, J. State-led creative/cultural city making and its contestations in East Asia: A multi-scalar analysis of the entrepreneurial state and the creative class. Geoforum 2019, 106, 305-309. [CrossRef]

6. Li, M.-C. Creative Cities and the Rise of Creative Industries in the UK. J. Public Adm. 2008, 4, 93-100, 127. (In Chinese)

7. Feng, S.-L.; Tan, Y.; Huang, N.; Gong, L.-T. Heterogeneity of matching degree between professional and employment industry in the perspective of registered residence system-Based on the analysis of employment data of 2008-2014 graduates of Peking University. Econ. Sci. 2017, 5, 113-128. (In Chinese) [CrossRef]

8. Liu, X.-Y.; Jin, N. Reorientation of the urban policy of "fighting for talents"-An analysis focusing on young mobile talents. China Youth Stud. 2019, 9, 47-53. (In Chinese) [CrossRef]

9. Clark, T.N. (Ed.) The City as an Entertainment Machine; Lexington Books: Lanham, MD, USA, 2003; ISBN 978-0-76230-541-4.

10. Glaeser, E.L. Triumph of the City: How Our Greatest Invention Makes Us Richer, Smarter, Greener, Healthier and Happier; Penguin Random House: London, UK, 2012; ISBN 9780143120544.

11. Zhang, J.-N.; Li, L.-X. Evolution and Influencing Factors of Spatial Distribution Pattern of Talents in Pearl River Delta. J. Sun Yat-sen Univ. 2020, 2. (In Chinese) [CrossRef]

12. Wang, Q.; Dong, Y.-L. Research on the Influencing Factors of Creative Class Agglomeration in the Yangtze River Delta. Mod. Econ. 2020, 6. (In Chinese) [CrossRef]

13. Basant, R.; Pankaj, C. Role of Educational and R\&D Institutions in City Clusters: An Exploratory Study of Bangalore and Pune Regions in India. World Dev. 2006, 35. [CrossRef]

14. Feser, E.; Renski, H.; Goldstein, H. Clusters and Economic Development Outcomes: An Analysis of the Link Between Clustering and Industry Growth. Econ. Dev. Q. 2008, 22, 324-344. [CrossRef]

15. Jiang, Y.; Wu, K.-L. Research on the Model of Influencing Factors of Creative Industry Districts Based on Factor Analysis-Taking Hangzhou's Four Creative Industry Districts as Examples. Shanghai J. Econ. 2009, 1. (In Chinese) [CrossRef]

16. Florida, R.; Mellander, C.; Adler, P. Handbook of Creative Cities; Andersson, D.E., Mellander, C., Eds.; Elgar: Cheltenham, UK, 2011; ISBN 978-0-85793-639-4.

17. Silver, D.A.; Clark, T.N. Scenescapes: How Qualities of Place Shape Social Life; The University of Chicago Press: Chicago, IL, USA, 2016; ISBN 978-0-226-35685-3.

18. Navarro, C.J.; Clark, T.N. Cultural Policy in European Cities: An Analysis from the Cultural Agenda of Mayors. Eur. Soc. 2012, 14, 636-659. [CrossRef]

19. Wu, J. The frontier of Urban Sociology: A review of Scenes Theory. Sociol. Rev. China 2014, 2, 90-95. (In Chinese)

20. Wang, N. Local consumerism, urban amenities and industrial structure optimization-Industrial transformation and upgrading from the perspective of consumption Sociology. Sociol. Study 2014, 29, 24-48. (In Chinese) [CrossRef]

21. Chen, B.; Wu, Y.-M.-R. Research on the development of urban creative community from the perspective of Scenes Theory. $J$. Shenzhen Univ. 2017, 34, 40-46. (In Chinese)

22. Qi, J.; Qi, R. Urban cultural innovation from the perspective of Buzz Theory. Theory Mon. 2020, 10, 89-98. (In Chinese) [CrossRef]

23. Hutton, T. The New Economy of the inner city. Cities 2004, 21, 21. [CrossRef]

24. Drinkwater, B.; Platt, S. Urban development process and creative clustering: The film industry in Soho and Beyoglu. Urban Des. Int. 2015, 21. [CrossRef]

25. Wenting, R.; Atzema, O.; Frenken, K. Urban Amenities and Agglomeration Economies? The Locational Behaviour and Economic Success of Dutch Fashion Design Entrepreneurs. Urban Stud. 2011, 48, 1333-1352. [CrossRef]

26. Murphy, E.; Fox-Rogers, L.; Redmond, D. Location Decision Making of "Creative" Industries: The Media and Computer Game Sectors in Dublin, Ireland: Location Decision Making of Creative Industries. Growth Chang. 2015, 46, 97-113. [CrossRef]

27. Falck, O.; Fritsch, M.; Heblich, S. The phantom of the opera: Cultural amenities, human capital, and regional economic growth. Labour Econ. 2011, 18, 755-766. [CrossRef]

28. Haisch, T.; Klöpper, C. Location Choices of the Creative Class: Does Tolerance Make a Difference? J. Urban Aff. 2015, 37, 233-254. [CrossRef]

29. Rodríguez-Gulías, M.J.; Fernández-López, S.; Rodeiro-Pazos, D. Innovation in Cultural and Creative Industries Firms with an Academic Origin (CCI-USOs): The Role of Regional Context. Technovation 2020, 92, 102044. [CrossRef]

30. Hutton, T.A. Spatiality, Built Form, and Creative Industry Development in the Inner City. Env. Plan A 2006, 38, 1819-1841. [CrossRef]

31. Wu, J. Scenes Theory: A New Perspective of using Cultural Factors to Promote Urban Development. Hunan Soc. Sci. 2017, 2, 175-182. (In Chinese) 
32. Jeong, $\mathrm{H}$. The role of the arts and bohemia in sustainable transportation and commuting choices in Chicago, Paris, and Seoul. J. Urban Aff. 2018, 1-26. [CrossRef]

33. Zhao, H.-X.; Zheng, X.-M. Research Status and Prospects of Work Mission. Bus. Manag. J. 2013, 10. (In Chinese) [CrossRef]

34. Zukin, S. The Cultures of Cities; Blackwell: Malden, MA, USA, 1995; ISBN 978-1-557-86437-6.

35. Lloyd, R. Neo-Bohemia: Art and Commerce in the Postindustrial City; Routledge: New York, NY, USA, 2006 ; ISBN 9780415870979.

36. Markusen, A. Urban development and the politics of a creative class: Evidence from a study of artists. Environ. Plan. 2006, 38, 1921-1940. [CrossRef]

37. Markusen, A. Creative cities: A 10-year research agenda. J. Urban Aff. 2014, 36, 567-589. [CrossRef]

38. Jeong, H.; Patterson, M. Starchitects in Bohemia: An Exploration of Cultural Cities from the 'Top-Down' and 'Bottom-Up'. Urban Aff. Rev. 2020. [CrossRef]

39. Ye, X.-Q.; Chen, W. Research on the Comprehensive Attraction of Chinese Cities to Scientific and Technological Innovation Talents-Construction and Demonstration of Evaluation Index System based on Amenities Theory. Stud. Sci. Sci. 2019. (In Chinese) [CrossRef]

40. Hu, X.-W. The Age of Creative Economy and New Opportunities for the City. Urban Probl. 2006, 5, 21-27. (In Chinese)

41. Chengdu New Economy ‘Double Thousand’ Press Conference Successfully Held. Available online: http://gk.chengdu.gov.cn/ govInfo/ detail.action?id=2793215\&tn=2 (accessed on 1 December 2020). (In Chinese)

42. Kloosterman, R.C. Cultural Amenities: Large and Small, Mainstream and Niche-A Conceptual Framework for Cultural Planning in an Age of Austerity. Eur. Plan. Stud. 2014, 22, 2510-2525. [CrossRef]

43. Notice of Chengdu New Economic Development Committee and Chengdu Finance Bureau on Organizing and Applying for Chengdu Future Scenes Laboratory. Available online: http:/ /gk.chengdu.gov.cn/govInfo/detail.action?id=2725422\&tn=2 (accessed on 6 January 2021). (In Chinese)

44. Jacobs, J. The Death and Life of Great American Cities; Random House: New York, NY, USA, 1961; ISBN 978-0-394-42159-9.

45. Jiang, H. Urban Spirit and the Shaping of Modern Urban Image. Commer. Times 2007, 10, 2. (In Chinese)

46. Tao, Q.-Q. Homogenization of Urban Space: Essence, Problems and Transcendence. Master's Thesis, Suzhou University, Suzhou, China, April 2016. (In Chinese)

47. Chengdu's Immersive Experience of New Scenes Drives the Upsurge of Culture and Tourism Consumption. Available online: http:/ / gk.chengdu.gov.cn/govInfo/detail.action?id=2840081\&tn=2 (accessed on 27 January 2021). (In Chinese)

48. Audretsch, D.B.; Mahmood, T. Firm Selection and Industry Evolution: The Post-Entry Performance of New Firms. J. Evol. Econ. 1994, 4, 243-260. [CrossRef] 